\title{
Project Delivery System Decision Making using Pythagorean Fuzzy TOPSIS
}

\author{
Limin $\mathrm{Su}^{1}$, Huimin $\mathrm{Li}^{2,3,4^{*}}$, Yongchao Cao ${ }^{2,3}$, Lelin $\mathrm{Lv}^{2,3}$ \\ ${ }^{1}$ School of Management and Economics, North China University of Water Resources and Electric Power \\ No. 136, Jinshui Road, 450046, Zhengzhou, China \\ E-mail.suliminlove2010@163.com
}

${ }^{2 *}$ Department of Construction Engineering and Management, North China University of Water Resources and Electric Power

No. 136, Jinshui Road, 450046, Zhengzhou, China

E-mail.lihuimin3646@163.com

*Corresponding author: lihuimin3646@163.com

${ }^{3}$ Henan Key Laboratory of Water Environment Simulation and Treatment

No. 136, Jinshui Road, 450046, Zhengzhou, China

E-mail.18638188626@163.com

${ }^{4}$ Collaborative Innovation Center of Water Resources Efficient Utilization and Protection Engineering No. 136, Jinshui Road, 450046, Zhengzhou, China

E-mail.13253671135@163.com

cross'ref http://dx.doi.org/10.5755/j01.ee.30.4.22041

The decision making of project delivery systems is a complex process, which is also a critical task for owners. The complexity problem arises from the uncertainty of decision making environment and construction project itself. Pythagorean fuzzy set (PFS), as an extension from intuitionistic fuzzy set (IFS) to deal with uncertainty information, has attracted more scholars' attention in the decision making area. This paper aims to develop a project delivery systems decision making approach under Pythagorean fuzzy environment. The main contributions of this paper are as follows: (1) Three similarity measures (i.e., 1type PFSs similarity measure, 2-type PFSs weighted similarity measure, 3-type PFSs weighted similarity measure) are developed, and their properties are also investigated. (2) An improved TOPSIS decision making framework is further established with PFSs information, in which the proposed similarity measures are employed to measure the similarity degree between each alternative and positive ideal solution and negative ideal solution. (3) A project delivery system decision making method using Pythagorean fuzzy TOPSIS decision making framework. Finally, a case study of the selection of project delivery systems is presented to prove the performance of the proposed decision making method.

Keywords: Project Delivery System; Pythagorean Fuzzy Sets; Similarity Measure; Pythagorean Fuzzy TOPSIS Method.

\section{Introduction}

A project delivery system (PDS) defines the relationship between project participants, and how a proposed project is delivered from the contractor to the owner (ASCE, 1988; Chen, et al., 2011). And PDS totally affects the construction performance including schedule, cost and quality (Blayse \& Manley, 2004; Chan, et al., 2001; Khalil, 2002; Mollaoglukorkmaz, et al., 2013; Shane, et al., 2013). The types of PDSs in construction industry practice can be selected, including design-bid-build (DBB), design-build (DB), construction management at risk (CM-at risk), engineering-procurement-construction (EPC), and integrated project delivery (IPD) (Chen, et al., 2010; Shi, et al., 2014; Qiang et al., 2015; Li et al., 2015) Selecting a suitable PDS for a construction project is a key task for an owner in the planning stage.

Quite a lot of research works focus on PDS selection decision making (Liu et al., 2015; Li et al., 2015). Analytical hierarchical process (AHP) was widely applied in the topic of PDS selection (Alhazmi \& Mccaffer, 2000; Khalil, 2002; Mafakheri et al., 2007; Mahdi \& Alreshaid, 2005). But
Belton and Stewart (2002) argued that AHP lacks sound statistical theory and is incapable to adequately handle uncertainty information. Some researchers applied multiattribute utility to tackle the PDSs decision problem (Love et al., 1998; Chan et al., 2001; Oyetunji \& Anderson, 2006; Chen et al., 2011). However, the utility values of the indicators cannot totally reflect the project characteristics. Fuzzy set is employed to deal with PDSs selection problem (Ng et al., 2005; Hong et al., 2008; Chen et al., 2011; Wang et al., 2014). Actually, the PDSs selection problem can be considered as a multi-criteria decision making (MCDM) problems. Li et al. (2015) developed a MCDM model integrating information entropy and unascertained set to select PDS for a construction project. A group decision making model using Interval-valued intuitionistic fuzzy set (IVIFS) theory for PDS selection was proposed by An et al. (2018).

Recently, MCDM problems have been applied in a wide research field (Podviezko \& Podvezko, 2014; Zhou et al., 2015; Chen 2015; Hanine et al., 2016; Pourahmadi et al., 2017; Fahmi et al., 2017; Zhang et al., 2017; Gitinavard et al., 2017; Potharaju \& Sreedevi, 2018; Ren et al., 2018). 
From the existing research, decision making methods and preference information are important factors in decision making process, in which desirable alternative solution can be chosen by selecting a decision making method and providing preference information from a decision maker.

As one of the popular MCDM methods, Technique for Order Preference by Similarity to an Ideal Solution (TOPSIS) method, firstly introduced by Hwang and Yoon (Hwang \& Yoon, 1981), is introduced to many decision making topics. The essential goal of the TOPSIS technique is that the most desired alternative should have not only the farthest distance from the negative ideal solution, but also the shortest distance from the positive ideal solution (Onat et al., 2016). Over the past decades, a lot of researchers have applied TOPSIS, modified or extended TOPSIS method to solve decision making problems in a different field (Boran et al., 2009; Chen et al., 2016; Joshi \& Kumar, 2016; Li \& Wu, 2016; Liang et al., 2018; Liu, 2014; Nehi \& Keikha, 2016; Tian et al., 2015). Zadeh (1965) introduced Fuzzy set theory. It has been widely employed to model uncertainty in realworld. Fuzzy sets were extended to Atanassov's intuitionistic fuzzy sets (IFSs) (Atanassov, 1986; Krassimir \& Atanassov, 1989). The Pythagorean fuzzy set (PFS) (Yager, 2013, 2014) has become an effective tool for solving the multiple attribute decision making (MADM) problems under uncertainty. Many different cases under uncertainty information have been investigated in the literature.

From the existing research results, we can easily find that distance and similarity measures are vital tools for calculating the relative closeness coefficient. Liang and $\mathrm{Xu}$ (2017) established a new improved TOPSIS decision making method under hesitant Pythagorean fuzzy sets, in which the geometric distance was used to measure the closeness degree between ideal solution and each alternative. Aikhuele and Turan (2017) developed an intuitionistic fuzzy TOPSIS model based on exponential-related function. In their study, the exponential-related function served as a mean to compute relative closeness coefficients by distance from each alternative to the intuitionistic fuzzy negative and positive ideal solutions. Zhang and $\mathrm{Xu}$ (2015) gave an extension of TOPSIS with PFS, and defined a distance measure from each alternative to the Pythagorean fuzzy negative ideal solution and the Pythagorean fuzzy positive ideal solution, respectively.

An abundant theoretical support is provided through reviewing the existing research, while further research should be developed on two main aspects. (1) The existing similarity measure ignored the confidence degrees of experts when they give evaluation values in the evaluation process. Actually, the confidence degrees from decision experts play an important role to ensure the effective evaluation information for all types of PDSs in the selection process of PDSs. Generally, it needs to find a simple and intuitive way to make a reliable decision making. (2) The existing similarity measure, which is used to depict the "closeness" degree between each alternative and ideal alternative, is generally considered from the problem rather than considering the psychological behavior of experts or decision maker. To bridge this gap, this paper aims to develop a Pythagorean fuzzy TOPSIS approach applied to PDSs selection. For the purpose, this paper firstly presents three new similarity measures under PFSs based on minimum and maximum operators. Secondly, an improved TOPSIS method using the proposed similarity measures is established. Thirdly, improved TOPSIS approach is employed to PDS selection under Pythagorean fuzzy environment.

The remainder of the paper is organized as follows. Decision making framework for selection PDSs is given in Section 2. In Section 3, methodology for PDSs selection is introduced, including preliminaries about Pythagorean fuzzy sets and three new similarity measures for PFSs are presented in this paper. In Section 4, a Pythagorean fuzzy TOPSIS method based on similarity measure for PDSs selection is developed. A case study about selection of PDS is presented to illustrate the effectiveness of the proposed method in section 5. The conclusions are drawn in Section 6.

\section{Decision Making Framework for Selection PDSs}

For a proposed construction project, the alternative PDS can be selected including DBB, DB, CM-at risk, and EPC. The study of Mafakheri et al. (2007) had shown that there were many factors that affecting the selection of an appropriate PDS. The selection of PDSs is a typical decision making problem, the decision making indicators for selection PDS can be illustrated as Figure 1. Based on them, the appropriate PDS can be obtained through choosing a matching approach, and the selection decision making process is shown as in Figure 2.

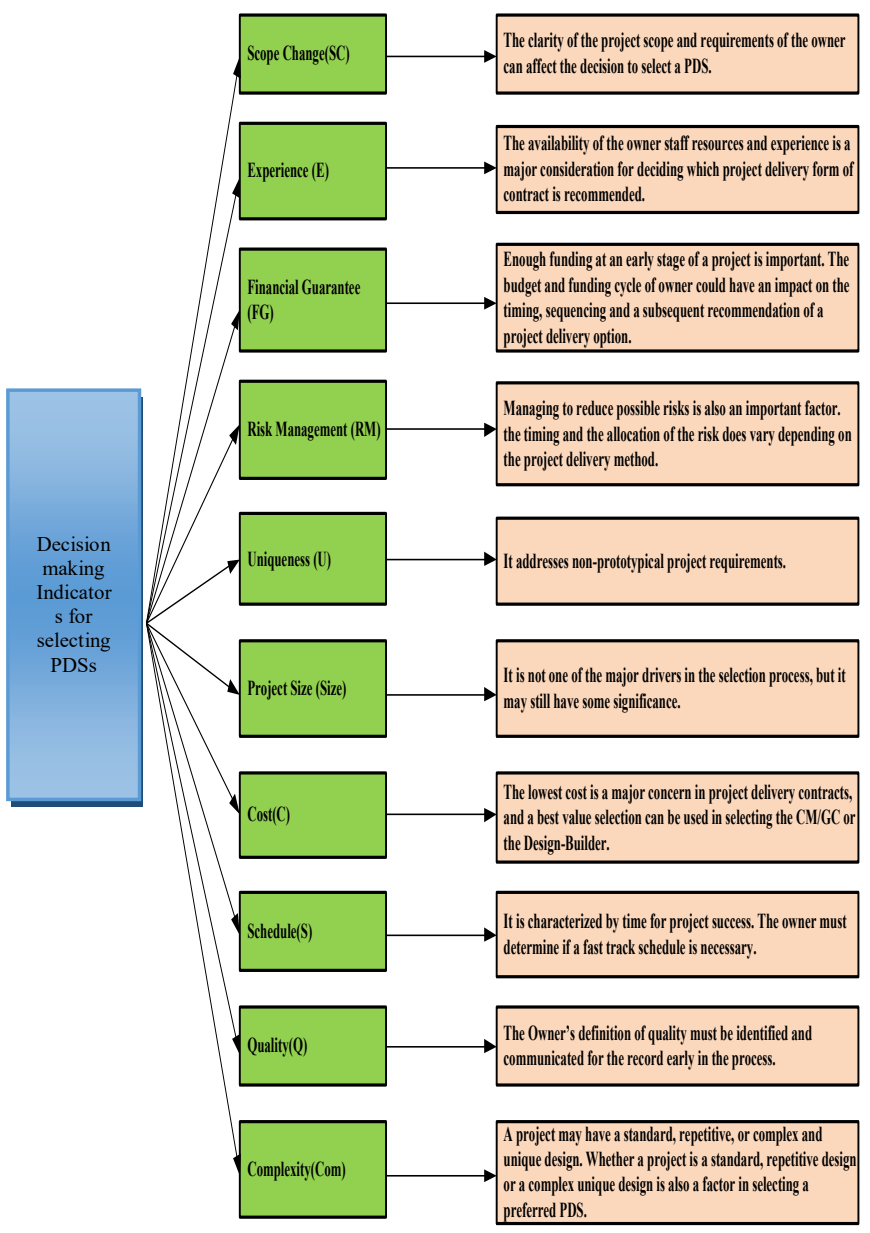

Figure 1. Decision Making Indicators for Selection PDSs 


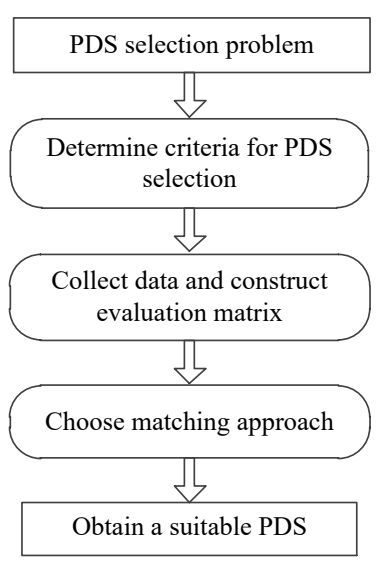

Figure 2. The Flow Chart for PDSs Selection

\section{Methodology for PDSs Selection}

This section presents the methodology for selecting PDSs. Following the preliminaries about PFSs and new similarity measures are introduced.

\section{Preliminaries about PFSs}

This subsection will give the concepts of PFSs and their relevant operations.

Definition 1 (Yager, 2013, 2014) Assume that $X$ is a universe of discourse. The PFS $P$ in $X$ denoted as

$$
P=\left\{\left\langle x, u_{P}(x), v_{P}(x)\right\rangle \mid x \in X\right\}
$$

in which $u_{P}(x): X \rightarrow[0,1]$ is membership degree and $v_{P}(x): X \rightarrow[0,1]$ denotes the degree of non-membership of the element $x \in X$ to $P$ respectively, the degree of indeterminacy is $\pi_{P}(x)=\sqrt{1-u_{P}^{2}(x)-v_{P}^{2}(x)}$. And the PFS $P$ satisfies the condition $0 \leq u_{P}^{2}(x)+v_{P}^{2}(x) \leq 1$.

For convenience, $\left(u_{P}(x), v_{P}(x)\right)$ is called a PFN and denoted as $\bar{P}=\left(u_{\bar{P}}, v_{\bar{P}}\right)$.

Definition 2 A Pythagorean fuzzy set $P_{1}$ contains the other Pythagorean fuzzy set $P_{2}$, i.e., $P_{2} \subseteq P_{1}$, if and only if $u_{P_{1}}(x) \geq u_{P_{2}}(x), v_{P_{1}}(x) \leq v_{P_{2}}(x)$ for all $x \in X$.

Definition 3 (Zhang \& Xu, 2015) Assume that $p=\left(u_{p}, v_{p}\right)$ is a PFN, then we define the score function of $p$ can be defined as follows:

$$
\mathrm{S}(p)=\left(u_{p}\right)^{2}-\left(v_{p}\right)^{2}
$$

where $\mathrm{S}(p) \in[-1,1]$.

Definition 4 (Peng \& Yang, 2015) Let $p=\left(u_{p}, v_{p}\right)$ be a PFN, then the accuracy function of $p$ can be defined as follows:

$$
\mathrm{K}(p)=\left(u_{p}\right)^{2}+\left(v_{p}\right)^{2}
$$

where $\mathrm{K}(p) \in[0,1]$.
For any two PFNs $p_{1}$ and $p_{2}$, the comparison rules are shown as follows (Peng and Yang, 2015):

(I) if $\mathrm{S}\left(p_{1}\right)<\mathrm{S}\left(p_{2}\right)$, then $p_{1} \prec \quad$;

(II) if $\mathrm{S}\left(p_{1}\right)=\mathrm{S}\left(p_{2}\right)$, then,

(a) if $\mathrm{K}\left(p_{1}\right)<\mathrm{K}\left(p_{2}\right)$, then $p_{1} \prec \quad$;

(b) if $\mathrm{K}\left(p_{1}\right)=\mathrm{K}\left(p_{2}\right)$, then $p_{1} \square$.

Definition 5 (Yager, 2014) Assume that $p_{i}=\left(u_{i}, v_{i}\right)$ $\left(i=1,2, \ldots \quad\right.$ is a PFN set and $w=\left(w_{1}, w_{2}, \ldots \quad \ldots\right.$, be the weight vector from $p_{i}\left(i=1,2, \ldots \quad\right.$, where $\sum_{i=1}^{n} w_{i}=1$, then a PFWA operator is expressed as:

$$
\operatorname{PFWA}\left(p_{1}, p_{2}, \ldots, \quad\left(\sum_{i=1}^{n} w_{i} u_{i}, \sum_{i=1}^{n} w_{i} v_{i}\right) .\right.
$$

\section{New Similarity Measures Between PFSs}

In this subsection, three new similarity measures between PFSs based on maximum and minimum operators, and their properties are presented.

Generally, a similarity measure between two sets $X_{1}$ and $X_{2}$ is a function defined as $\mathrm{r}: F(X) \times F(X) \rightarrow[0,1]$, which satisfies the following properties:

(P1) $\mathrm{r}\left(X_{1}, X_{2}\right)=\mathrm{r}\left(X_{2}, X_{1}\right)$;

(P2) $\mathrm{r}\left(X_{1}, X_{2}\right)=1$ if $X_{1}=X_{2}$;

(P3) $\mathrm{r}\left(X_{1}, X_{2}\right)=\mathrm{r}\left(X_{2}, X_{1}\right)$;

(P4) $\mathrm{r}\left(X_{1}, X_{3}\right) \leq \mathrm{r}\left(X_{1}, X_{2}\right)$ and $\mathrm{r}\left(X_{1}, X_{3}\right) \leq \mathrm{r}\left(X_{2}, X_{3}\right)$ if $X_{1} \subseteq X_{2} \subseteq X_{3}$ for a set $X_{3}$.

Proposition 1 Assume that $X=\left\{x_{1}, x_{2}, \ldots \quad \ldots\right.$ is a given set, $P_{1}$ and $P_{2}$ are two PFSs, then 1-type PFSs similarity measure

$$
\begin{aligned}
\mathrm{r}_{1}\left(P_{1}, P_{2}\right)= & \frac{1}{2 n} \sum_{i=1}^{n}\left(\frac{\min \left(u_{P_{1}}\left(x_{i}\right), u_{P_{2}}\left(x_{i}\right)\right)}{\max \left(u_{P_{1}}\left(x_{i}\right), u_{P_{2}}\left(x_{i}\right)\right)}\right. \\
& \left.+\frac{\min \left(v_{P_{1}}\left(x_{i}\right), v_{P_{2}}\left(x_{i}\right)\right)}{\max \left(v_{P_{1}}\left(x_{i}\right), v_{P_{2}}\left(x_{i}\right)\right)}\right)
\end{aligned}
$$

should satisfy the following properties:

(P1) $0 \leq \mathrm{r}_{1}\left(P_{1}, P_{2}\right) \leq 1$;

(P2) $\mathrm{r}_{1}\left(P_{1}, P_{2}\right)=1$ if $P_{1}=P_{2}$;

(P3) $\mathrm{r}_{1}\left(P_{1}, P_{2}\right)=\mathrm{r}_{1}\left(P_{2}, P_{1}\right)$;

(P4) $\mathrm{r}_{1}\left(P_{1}, P_{3}\right) \leq \mathrm{r}_{1}\left(P_{1}, P_{2}\right)$ and $\mathrm{r}_{1}\left(P_{1}, P_{3}\right) \leq \mathrm{r}_{1}\left(P_{2}, P_{3}\right)$ if $P_{1} \subseteq P_{2} \subseteq P_{3}$ for a PFS $P_{3}$. 
Limin Su, Huimin Li, Yongchao Cao, Lelin Lv. Project Delivery System Decision Making using Pythagorean...

Proof. Properties (P1)-(P3) can be easily verified. Therefore, we only prove the property (P4). Let $P_{1} \subseteq P_{2} \subseteq P_{3}$, then

$$
\begin{aligned}
& u_{P_{1}}\left(x_{i}\right) \leq u_{P_{2}}\left(x_{i}\right) \leq u_{P_{3}}\left(x_{i}\right), \\
& v_{P_{1}}\left(x_{i}\right) \geq v_{P_{2}}\left(x_{i}\right) \geq v_{P_{3}}\left(x_{i}\right)
\end{aligned}
$$

for every $x_{i} \in X$. So, we can obtain that

$$
\begin{aligned}
& \min \left\{u_{P_{1}}\left(x_{i}\right), u_{P_{2}}\left(x_{i}\right)\right\}=u_{P_{1}}\left(x_{i}\right) ; \\
& \max \left\{u_{P_{1}}\left(x_{i}\right), u_{P_{2}}\left(x_{i}\right)\right\}=u_{P_{2}}\left(x_{i}\right) ; \\
& \min \left\{v_{P_{1}}\left(x_{i}\right), v_{P_{2}}\left(x_{i}\right)\right\}=v_{P_{2}}\left(x_{i}\right) ; \\
& \max \left\{v_{P_{1}}\left(x_{i}\right), v_{P_{2}}\left(x_{i}\right)\right\}=v_{P_{1}}\left(x_{i}\right),
\end{aligned}
$$

thus, the 1-type PFSs similarity measure between two PFSs $P_{1}$ and $P_{2}$ can be obtained as follows:

$$
\begin{aligned}
\mathrm{r}_{1}\left(P_{1}, P_{2}\right)= & \frac{1}{2 n} \sum_{i=1}^{n}\left(\frac{\min \left\{u_{P_{1}}\left(x_{i}\right), u_{P_{2}}\left(x_{i}\right)\right\}}{\max \left\{u_{P_{1}}\left(x_{i}\right), u_{P_{2}}\left(x_{i}\right)\right\}}\right. \\
& \left.+\frac{\min \left\{v_{P_{1}}\left(x_{i}\right), v_{P_{2}}\left(x_{i}\right)\right\}}{\max \left\{v_{P_{1}}\left(x_{i}\right), v_{P_{2}}\left(x_{i}\right)\right\}}\right) \\
& =\frac{1}{2 n} \sum_{i=1}^{n}\left\{\frac{u_{P_{1}}\left(x_{i}\right)}{u_{P_{2}}\left(x_{i}\right)}+\frac{v_{P_{2}}\left(x_{i}\right)}{v_{P_{1}}\left(x_{i}\right)}\right\} .
\end{aligned}
$$

Similarly, the 1-type PFSs similarity measure between two PFSs $P_{1}$ and $P_{3}$ is:

$$
\begin{aligned}
\mathrm{r}_{1}\left(P_{1}, P_{3}\right)= & \frac{1}{2 n} \sum_{i=1}^{n}\left(\frac{\min \left\{u_{P_{1}}\left(x_{i}\right), u_{P_{3}}\left(x_{i}\right)\right\}}{\max \left\{u_{P_{1}}\left(x_{i}\right), u_{P_{3}}\left(x_{i}\right)\right\}}\right. \\
& \left.+\frac{\min \left\{v_{P_{1}}\left(x_{i}\right), v_{P_{3}}\left(x_{i}\right)\right\}}{\max \left\{v_{P_{1}}\left(x_{i}\right), v_{P_{3}}\left(x_{i}\right)\right\}}\right) \\
& =\frac{1}{2 n} \sum_{i=1}^{n}\left\{\frac{u_{P_{1}}\left(x_{i}\right)}{u_{P_{3}}\left(x_{i}\right)}+\frac{v_{P_{3}}\left(x_{i}\right)}{v_{P_{1}}\left(x_{i}\right)}\right\}
\end{aligned}
$$

and the 1-type PFSs similarity measure between two PFSs $P_{2}$ and $P_{3}$ is:

$$
\begin{aligned}
\mathrm{r}_{1}\left(P_{2}, P_{3}\right)= & \frac{1}{2 n} \sum_{i=1}^{n}\left(\frac{\min \left\{u_{P_{2}}\left(x_{i}\right), u_{P_{3}}\left(x_{i}\right)\right\}}{\max \left\{u_{P_{2}}\left(x_{i}\right), u_{P_{3}}\left(x_{i}\right)\right\}}\right. \\
& \left.+\frac{\min \left\{v_{P_{2}}\left(x_{i}\right), v_{P_{3}}\left(x_{i}\right)\right\}}{\max \left\{v_{P_{2}}\left(x_{i}\right), v_{P_{3}}\left(x_{i}\right)\right\}}\right) \\
& =\frac{1}{2 n} \sum_{i=1}^{n}\left\{\frac{u_{P_{2}}\left(x_{i}\right)}{u_{P_{3}}\left(x_{i}\right)}+\frac{v_{P_{3}}\left(x_{i}\right)}{v_{P_{2}}\left(x_{i}\right)}\right\} .
\end{aligned}
$$

For the proof of (P4), we only comparison the right terms of formulas (6) and (7) in curly braces. From formulas (4) and (5), we can easily obtain the result through comparing numerator or denominator in the corresponding terms. Therefore, $\mathrm{r}_{1}\left(P_{1}, P_{3}\right) \leq \mathrm{r}_{1}\left(P_{1}, P_{2}\right)$.
Similarly, from formulas (7) and (8), we get $\mathrm{r}_{1}\left(P_{1}, P_{3}\right) \leq \mathrm{r}_{1}\left(P_{2}, P_{3}\right)$.

So the 1-type PFSs similarity measure $\mathrm{r}_{1}\left(P_{1}, P_{2}\right)$ satisfies the property (P4).

When we consider the importance in the two terms, i.e., membership, non-membership, in a PFN, we should take the weights of the two terms in formula (3) into account. Therefore, we develop another similarity measure between PFSs.

Proposition 2 Assume that $X=\left\{x_{1}, x_{2}, \ldots \ldots\right.$ is a given set, $P_{1}$ and $P_{2}$ be two PFSs, then 2-type PFSs weighted similarity measure

$$
\begin{aligned}
\mathrm{r}_{2}\left(P_{1}, P_{2}\right) & =\frac{1}{n} \sum_{i=1}^{n}\left(\alpha \frac{\min \left(u_{P_{1}}\left(x_{i}\right), u_{P_{2}}\left(x_{i}\right)\right)}{\max \left(u_{P_{1}}\left(x_{i}\right), u_{P_{2}}\left(x_{i}\right)\right)}\right. \\
& \left.+\beta \frac{\min \left(v_{P_{1}}\left(x_{i}\right), v_{P_{2}}\left(x_{i}\right)\right)}{\max \left(v_{P_{1}}\left(x_{i}\right), v_{P_{2}}\left(x_{i}\right)\right)}\right)
\end{aligned}
$$

should satisfy the following properties:

(P1) $0 \leq \mathrm{r}_{2}\left(P_{1}, P_{2}\right) \leq 1$;

(P2) $\mathrm{r}_{2}\left(P_{1}, P_{2}\right)=1$ if $P_{1}=P_{2}$;

(P3) $\mathrm{r}_{2}\left(P_{1}, P_{2}\right)=\mathrm{r}_{2}\left(P_{2}, P_{1}\right)$;

(P4) $\mathrm{r}_{2}\left(P_{1}, P_{3}\right) \leq \mathrm{r}_{2}\left(P_{1}, P_{2}\right)$ and $\mathrm{r}_{2}\left(P_{1}, P_{3}\right) \leq \mathrm{r}_{2}\left(P_{2}, P_{3}\right)$ if $P_{1} \subseteq P_{2} \subseteq P_{3}$ for a PFS $P_{3}$, where $\alpha, \beta$ are the weights of the two elements (i.e., membership degree, nonmembership degree) in a PFS and $\alpha+\beta=1$. Especially, when $\alpha=\beta=1 / 2$, formula (9) reduces to formula (3).

With the help of the proof of Proposition 1, Proposition 2 can be proved.

Furthermore, if the important differences are considered in the elements in a universe of discourse $X=\left\{x_{1}, x_{2}, \ldots \ldots\right.$, , the weight $w_{i}$ from every element $x_{i}(i=1,2, \cdots$, is needed to be taken into account. If $w_{i}$ is the weight from element $x_{i}(i=1,2, \cdots$, $w_{i} \in[0,1]$, and $\sum_{i=1}^{n} w_{i}=1$, and then the weighted similarity measure is given in next proposition.

Proposition 3 Assume that $X=\left\{x_{1}, x_{2}, \ldots\right.$, is a given set, $P_{1}$ and $P_{2}$ are two PFSs, the 3-type PFSs weighted similarity measure

$$
\begin{aligned}
\mathrm{r}_{3}\left(P_{1}, P_{2}\right) & =\sum_{i=1}^{n} w_{i}\left(\alpha \frac{\min \left(u_{P_{1}}\left(x_{i}\right), u_{P_{2}}\left(x_{i}\right)\right)}{\max \left(u_{P_{1}}\left(x_{i}\right), u_{P_{2}}\left(x_{i}\right)\right)}\right. \\
& \left.+\beta \frac{\min \left(v_{P_{1}}\left(x_{i}\right), v_{P_{2}}\left(x_{i}\right)\right)}{\max \left(v_{P_{1}}\left(x_{i}\right), v_{P_{2}}\left(x_{i}\right)\right)}\right)
\end{aligned}
$$

should satisfy the following properties:

(P1) $0 \leq \mathrm{r}_{3}\left(P_{1}, P_{2}\right) \leq 1$; 
(P2) $\mathrm{r}_{3}\left(P_{1}, P_{2}\right)=1$ if $P_{1}=P_{2}$;

(P3) $\mathrm{r}_{3}\left(P_{1}, P_{2}\right)=\mathrm{r}_{3}\left(P_{2}, P_{1}\right)$;

(P4) $\mathrm{r}_{3}\left(P_{1}, P_{3}\right) \leq \mathrm{r}_{3}\left(P_{1}, P_{2}\right)$ and $\mathrm{r}_{3}\left(P_{1}, P_{3}\right) \leq \mathrm{r}_{3}\left(P_{2}, P_{3}\right)$ if $P_{1} \subseteq P_{2} \subseteq P_{3}$ for a PFS $P_{3}$, where $\alpha, \beta$ are the weights of the two elements (i.e., membership, non-membership) in a PFS and $\alpha+\beta=1$. Especially, when $w_{1}=w_{2}=\cdots \quad / n$, formula (10) reduces to formula (9).

Proof of Proposition 3 can be obtained from the proof of Proposition 1.

Example 1. Assume that there are three PFSs in a universe of discourse $X=\left\{x_{1}, x_{2}, x_{3}\right\}$ :

$$
\begin{aligned}
& P_{1}=\left\{\left\langle x_{1}, 0.3,0.8\right\rangle,\left\langle x_{2}, 0.4,0.7\right\rangle,\left\langle x_{3}, 0.5,0.6\right\rangle\right\} ; \\
& P_{2}=\left\{\left\langle x_{1}, 0.5,0.7\right\rangle,\left\langle x_{2}, 0.5,0.4\right\rangle,\left\langle x_{3}, 0.7,0.5\right\rangle\right\} ; \\
& P_{3}=\left\{\left\langle x_{1}, 0.9,0.3\right\rangle,\left\langle x_{2}, 0.8,0.3\right\rangle,\left\langle x_{3}, 0.8,0.4\right\rangle\right\},
\end{aligned}
$$

and $P_{1} \subseteq P_{2} \subseteq P_{3}$. By using formula (2), the 1-type similarity measures are as follows:

$$
\begin{aligned}
& \mathrm{r}_{1}\left(P_{1}, P_{2}\right)=\frac{1}{6}\left(\frac{0.3}{0.5}+\frac{0.7}{0.8}+\frac{0.4}{0.5}+\frac{0.4}{0.7}+\frac{0.5}{0.7}+\frac{0.5}{0.6}\right) \approx 0.7323 \\
& \mathrm{r}_{1}\left(P_{1}, P_{3}\right)=\frac{1}{6}\left(\frac{0.3}{0.9}+\frac{0.3}{0.8}+\frac{0.4}{0.8}+\frac{0.3}{0.7}+\frac{0.5}{0.8}+\frac{0.4}{0.6}\right) \approx 0.4881 ; \\
& \mathrm{r}_{1}\left(P_{2}, P_{3}\right)=\frac{1}{6}\left(\frac{0.5}{0.9}+\frac{0.3}{0.7}+\frac{0.5}{0.8}+\frac{0.3}{0.4}+\frac{0.7}{0.8}+\frac{0.4}{0.5}\right) \approx 0.6724,
\end{aligned}
$$

thus, $\mathrm{r}_{1}\left(P_{1}, P_{3}\right) \leq \mathrm{r}_{1}\left(P_{1}, P_{2}\right)$ and $\mathrm{r}_{1}\left(P_{1}, P_{3}\right) \leq \mathrm{r}_{1}\left(P_{2}, P_{3}\right)$ are obtained.

Let the weight values of the two terms in a PFS are $\alpha=0.55$ and $\beta=0.45$, by applying formula (9), then 2-type PFSs weighted similarity measures are as follows:

$$
\begin{aligned}
\mathrm{r}_{2}\left(P_{1}, P_{2}\right)= & \frac{1}{3}\left(0.55 \times \frac{0.3}{0.5}+0.45 \times \frac{0.7}{0.8}+0.55 \times \frac{0.4}{0.5}\right. \\
& \left.+0.45 \times \frac{0.4}{0.7}+0.55 \times \frac{0.5}{0.7}+0.45 \times \frac{0.5}{0.6}\right) \\
& \approx 0.7296 ; \\
\mathrm{r}_{2}\left(P_{1}, P_{3}\right)= & \frac{1}{3}\left(0.55 \times \frac{0.3}{0.9}+0.45 \times \frac{0.3}{0.8}+0.55 \times \frac{0.4}{0.8}\right. \\
& \left.+0.45 \times \frac{0.3}{0.7}+0.55 \times \frac{0.5}{0.8}+0.45 \times \frac{0.4}{0.6}\right) \\
& \approx 0.4879 ; \\
\mathrm{r}_{2}\left(P_{2}, P_{3}\right)= & \frac{1}{3}\left(0.55 \times \frac{0.5}{0.9}+0.45 \times \frac{0.3}{0.7}+0.55 \times \frac{0.5}{0.8}\right. \\
& \left.+0.45 \times \frac{0.3}{0.4}+0.55 \times \frac{0.7}{0.8}+0.45 \times \frac{0.4}{0.5}\right) \\
\approx & 0.6736 .
\end{aligned}
$$

Therefore, we have $\mathrm{r}_{2}\left(P_{1}, P_{3}\right) \leq \mathrm{r}_{2}\left(P_{1}, P_{2}\right)$ and

$$
\mathrm{r}_{2}\left(P_{1}, P_{3}\right) \leq \mathrm{r}_{2}\left(P_{2}, P_{3}\right) .
$$

Assume that three criteria's weight vector is $w=(0.4,0.3,0.3)$, and weight values of two terms (i.e., membership and non-membership degrees) in a PFS, are $\alpha=0.55$ and $\beta=0.45$. By applying formula (10), the 3-type PFSs weighted similarity measures are as follows:

$$
\begin{aligned}
\mathrm{r}_{3}\left(P_{1}, P_{2}\right)= & \left(0.55 \times 0.4 \times \frac{0.3}{0.5}+0.45 \times 0.3 \times \frac{0.7}{0.8}\right. \\
& +0.55 \times 0.3 \times \frac{0.4}{0.5}+0.45 \times 0.4 \times \frac{0.4}{0.7} \\
& \left.+0.55 \times 0.3 \times \frac{0.5}{0.7}+0.45 \times 0.3 \times \frac{0.5}{0.6}\right) \\
& \approx 0.7153 ; \\
\mathrm{r}_{3}\left(P_{1}, P_{3}\right)= & \left(0.55 \times 0.4 \times \frac{0.3}{0.9}+0.45 \times 0.3 \times \frac{0.3}{0.8}\right. \\
& +0.55 \times 0.3 \times \frac{0.4}{0.8}+0.45 \times 0.4 \times \frac{0.3}{0.7} \\
& \left.+0.55 \times 0.3 \times \frac{0.5}{0.8}+0.45 \times 0.3 \times \frac{0.4}{0.6}\right) \\
& \approx 0.4767 ; \\
\mathrm{r}_{3}\left(P_{2}, P_{3}\right)= & 0.55 \times 0.4 \times \frac{0.5}{0.9}+0.45 \times 0.3 \times \frac{0.3}{0.7} \\
& +0.55 \times 0.3 \times \frac{0.5}{0.8}+0.45 \times 0.4 \times \frac{0.3}{0.4} \\
& \left.+0.55 \times 0.3 \times \frac{0.7}{0.8}+0.45 \times 0.3 \times \frac{0.4}{0.5}\right) \\
& \approx 0.6706 .
\end{aligned}
$$

Thus, there are $\mathrm{r}_{3}\left(P_{1}, P_{3}\right) \leq \mathrm{r}_{3}\left(P_{1}, P_{2}\right)$ and

$$
\mathrm{r}_{3}\left(P_{1}, P_{3}\right) \leq \mathrm{r}_{3}\left(P_{2}, P_{3}\right) \text {. }
$$

\section{A Pythagorean Fuzzy TOPSIS Method Based on Similarity Measure for PDSs Selection}

In Pythagorean fuzzy environment, a given PDSs selection problem can be described as below.

We assume that $O=\left\{o_{1}, o_{2}, \ldots\right.$, is a given PDSs set, $C=\left\{c_{1}, c_{2}, \ldots \quad \ldots\right.$, is a criteria set affecting PDSs selection, and $W=\left\{w_{1}, w_{2}, \ldots \quad\right.$, is weight vector of criteria with $0 \leq w_{j} \leq 1$ and $\sum_{j=1}^{m} w_{j}=1$. Let $c_{j}\left(o_{i}\right)=\mathrm{p}\left(u_{i j}, v_{i j}\right)$ denotes the evaluation values of the $i$ th $\operatorname{PDS} o_{i}(i=1,2, \ldots$, with regard to the criteria $c_{j} \quad(j=1,2, \ldots, \quad$, then $U=\left(c_{j}\left(o_{i}\right)\right)_{n \times m}$ is a Pythagorean fuzzy matrix. Therefore, the PDSs selection problem with Pythagorean fuzzy setting is represented as:

$$
U=\left(c_{j}\left(o_{i}\right)\right)_{n \times m}=\left(\begin{array}{cccc}
\mathrm{p}\left(u_{11}, v_{11}\right) & \mathrm{p}\left(u_{12}, v_{12}\right) & \ldots & \\
\mathrm{p}\left(u_{21}, v_{21}\right) & \mathrm{p}\left(u_{22}, v_{22}\right) & \ldots & \vdots \\
\vdots & \vdots & \vdots & \vdots \\
\mathrm{p}\left(u_{n 1}, v_{n 1}\right) & \mathrm{p}\left(u_{n 1}, v_{n 1}\right) & \ldots &
\end{array}\right.
$$


According to the principle of TOPSIS, the distance between the optimal alternative and the positive ideal solution should be as close as possible, and the distance between the optimal alternative and the negative ideal solution should be as far as possible.

Thus, we firstly identify the best suitable PDS and the worst suitable PDS based on the following formulas:

Best suitable PDS:

$O^{+}=\left\{o_{1}^{+}, \ldots\right.$,

where $o_{j}^{+}=\max _{i}\left(\mathrm{p}\left(u_{i j}, v_{i j}\right)\right)$ for benefit criteria, while $o_{j}^{+}=\min _{i}\left(\mathrm{p}\left(u_{i j}, v_{i j}\right)\right)$ for cost criteria:

Worst suitable PDS:

$O^{-}=\left\{o_{1}^{-}, \ldots\right.$, ,

where $o_{j}^{-}=\min \left(\mathrm{p}\left(u_{i j}, v_{i j}\right)\right)$ for benefit criteria, while $o_{j}^{-}=\max _{i}\left(\mathrm{p}\left(u_{i j}, v_{i j}\right)\right)$ for cost criteria. For brevity, the best and worst suitable PDSs are rewritten as

$o_{j}^{+}=\left\{c_{j},\left(u_{j}^{+}, v_{j}^{+}\right) \mid j=1,2, \ldots \quad\right.$, and

$o_{j}^{-}=\left\{c_{j},\left(u_{j}^{-}, v_{j}^{-}\right) \mid j=1,2, \ldots, \quad, \quad\right.$,

respectively.

And the PFN $\mathrm{p}\left(u_{i j}, v_{i j}\right)$ is represented as

$\left(u_{i j}, v_{i j}\right)(i=1,2, \ldots \quad j=1,2, \ldots$

Applying the similarity measure in Proposition 3, the 3-type PFSs weighted similarity measures between the PDS $o_{i}$ and the best suitable PDS $O^{+}$can be calculated as follows:

$$
\mathrm{r}_{4}\left(o_{i}, O^{+}\right)=\sum_{j=1}^{m} w_{j}\left(\alpha \frac{\min \left(u_{i j}, u_{j}^{+}\right)}{\max \left(u_{i j}, u_{j}^{+}\right)}+\beta \frac{\min \left(v_{i j}, v_{j}^{+}\right)}{\max \left(v_{i j}, v_{j}^{+}\right)}\right)
$$

Analogously, the 3-type PFSs weighted similarity measures between the PDS $o_{i}$ and the worst suitable PDS $O^{-}$can be calculated as:

$$
\mathrm{r}_{4}\left(o_{i}, O^{-}\right)=\sum_{j=1}^{m} w_{j}\left(\alpha \frac{\min \left(u_{i j}, u_{j}^{-}\right)}{\max \left(u_{i j}, u_{j}^{-}\right)}+\beta \frac{\min \left(v_{i j}, v_{j}^{-}\right)}{\max \left(v_{i j}, v_{j}^{-}\right)}\right)
$$

So, the relative closeness value of the alternative $o_{i}$ with regard to the best suitable PDS $O^{-}$as follows:

$$
r_{i}=\frac{\mathrm{r}_{4}\left(o_{i}, O^{-}\right)}{\mathrm{r}_{4}\left(o_{i}, O^{-}\right)+\mathrm{r}_{4}\left(o_{i}, O^{+}\right)} .
$$

Obviously, $0<r_{i}<1$. Therefore, the ranking of all PDSs can be obtained by the relative closeness coefficient $r_{i}$. The greater the value $r_{i}$, the better suitable the corresponding PDS.

Based on the above statements, we further give a selection process using the proposed decision making method for PDS selection, as shown in Figure 3.

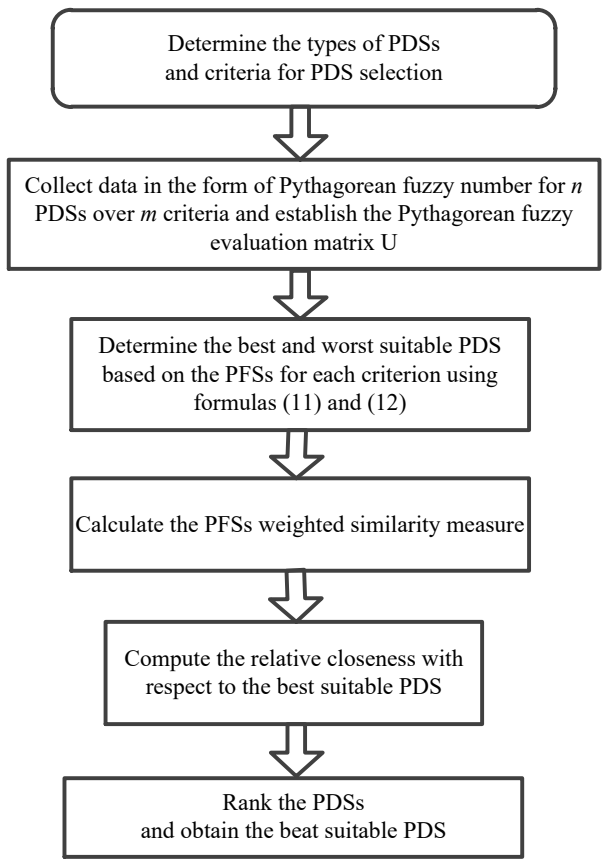

Figure 3. The Selection Process for PDS Selection Using the Proposed Method

Step 1: For a selection problem for PDS, the set of PDSs $O=\left\{o_{1}, o_{2}, \ldots \ldots\right.$ and the set of criteria $C=\left\{c_{1}, c_{2}, \ldots \ldots\right.$, are firstly determined. Furthermore, let the weight vector of criteria be $W=\left\{w_{1}, w_{2}, \ldots\right.$, . Then, the Pythagorean fuzzy matrix $U=\left(c_{j}\left(o_{i}\right)\right)_{n \times m}$ is constructed, where $c_{j}\left(o_{i}\right)=\mathrm{p}\left(u_{i j}, v_{i j}\right)$ is the evaluation value of PDS under the $j$ th criteria $c_{j}$ $(i=1,2, \ldots$

Step 2: Using formulas (11) and (12), we identify the best suitable PDS $O^{+}=\left\{o_{1}^{+}, o_{2}^{+}, \ldots\right.$, and the worst suitable PDS $O^{-}=\left\{o_{1}^{-}, o_{2}^{-}, \ldots\right.$

Step 3: By formulas (13) and (14), the 3-type PFSs weighted similarity measures between each PDS $o_{i}$ and the best suitable PDS $\mathrm{O}^{+}$and the worst suitable PDS $O^{-}$are calculated, $i=1,2, \ldots$

Step 4: From formula (15), we compute the relative closeness value $r_{i}$ of PDS $o_{i}$ about the best suitable PDS $\mathrm{O}^{+}, i=1,2, \ldots$

Step 5: Ranking the $m$ PDSs from the results obtained in Step 4.

\section{Case Study}

There is a real-world infrastructure project, the owner intends to select the most applicable delivery system from four delivery systems including design-build (DB), engineering-procurement-construction (EPC), construction management at risk method (CM at-Risk), and design-bidbuild (DBB), and their criteria and decision making 
framework are discussed in Section 2. To ensure the reliability and availability of data, the experienced experts from different fields should be invited to evaluate the project before carrying out the work.

Generally speaking, five or seven experts are invited in traditional engineering project to select PDSs. Firstly, the owners introduced their capacity and the goal of project. Secondly, further investigation to the construction site was conducted, and the related principals described the whole project in detail. Finally, according to the score chart and score criterion in advance, the evaluation results of the project from experts were obtained. Considering the practical situation of this project, five experts including engineers, academics, contractors and owners with rich experiences in this filed were invited, and aggregated all the evaluation information. The final result will be the evaluation matrix.

In this selection process, the four project delivery systems (DB, DBB, EPC, CM) form the set of delivery options, which is written as $O=\left\{o_{1}, o_{2}, o_{3}, o_{4}\right\}$. Similarly, the ten criteria (i.e., C, S, Q, Com, SC, E, FG, RM, U, Size) make up the criteria set $C=\left\{C_{1}, C_{2}, C_{3}, C_{4}, C_{5}, C_{6}\right.$, $\left.C_{7}, C_{8}, C_{9}, C_{10}\right\}$.For convenience, weight vector of criteria will be followed by equal weight method, that is, $w_{1}=w_{2}=\cdots \quad: \quad 0.1$, though there are many approaches for calculating weight. We assume that $\left(u_{i j}^{(l)}, v_{i j}^{(l)}\right)(i=1,2,3,4, j=1,2, \ldots \quad, l=1, \ldots \quad$ is the evaluation value from the $l$ th expert to delivery option $o_{i}$ with respect to criteria $c_{j}$, and $U_{4 \times 10}^{(l)}=\left(U_{i j}^{(l)}\right)_{4 \times 10}=\left(u_{i j}^{(l)}, v_{i j}^{(l)}\right)_{4 \times 10}$ denotes a PFN evaluation matrix from the $l$ th expert. Every expert should give the evaluation value $\left(u_{i j}^{(l)}, v_{i j}^{(l)}\right)(i=1,2,3,4, j=1, \ldots$, , the weight of each expert is a convenient way to set $W_{1}=\cdots \quad 0.2$. To utilize the proposed approach, we also assume that weights of membership and nonmembership degrees are $\alpha=0.55$ and $\beta=0.45$, respectively.

We assume that the Pythagorean fuzzy evaluation values matrixes are $U_{4 \times 10}^{(l)}=\left(U_{i j}^{(l)}\right)_{4 \times 10}=\left(u_{i j}^{(l)}, v_{i j}^{(l)}\right)_{4 \times 10}$ $(l=1, \ldots$, , where

$$
\begin{aligned}
& U_{4 \times 10}^{(1)}=\left(\begin{array}{lllll}
\mathrm{p}(0.7,0.3) & \mathrm{p}(0.7,0.5) & \mathrm{p}(0.6,0.5) & \mathrm{p}(0.6,0.2) & \mathrm{p}(0.6,0.2) \\
\mathrm{p}(0.8,0.4) & \mathrm{p}(0.8,0.4) & \mathrm{p}(0.7,0.4) & \mathrm{p}(0.7,0.4) & \mathrm{p}(0.8,0.4) \\
\mathrm{p}(0.6,0.4) & \mathrm{p}(0.5,0.3) & \mathrm{p}(0.6,0.3) & \mathrm{p}(0.8,0.3) & \mathrm{p}(0.5,0.3) \\
\mathrm{p}(0.5,0.2) & \mathrm{p}(0.7,0.5) & \mathrm{p}(0.7,0.3) & \mathrm{p}(0.6,0.3) & \mathrm{p}(0.7,0.3)
\end{array} ;\right. \\
& \begin{array}{lllll}
\mathrm{p}(0.6,0.3) & \mathrm{p}(0.7,0.4) & \mathrm{p}(0.6,0.4) & \mathrm{p}(0.4,0.4) & \mathrm{p}(0.6,0.3)
\end{array} \\
& \begin{array}{lllll}
\mathrm{p}(0.6,0.2) & \mathrm{p}(0.8,0.5) & \mathrm{p}(0.8,0.5) & \mathrm{p}(0.6,0.3) & \mathrm{p}(0.7,0.2)
\end{array} \\
& \begin{array}{lllll}
\mathrm{p}(0.8,0.4) & \mathrm{p}(0.7,0.3) & \mathrm{p}(0.8,0.2) & \mathrm{p}(0.7,0.2) & \mathrm{p}(0.4,0.5)
\end{array} \\
& \begin{array}{lllll}
\mathrm{p}(0.7,0.5) & \mathrm{p}(0.8,0.4) & \mathrm{p}(0.7,0.3) & \mathrm{p}(0.4,0.2) & \mathrm{p}(0.6,0.4)
\end{array}
\end{aligned}
$$

$$
\begin{aligned}
& \left(\begin{array}{llllll}
\mathrm{p}(0.5,0.7) & \mathrm{p}(0.6,0.7) & \mathrm{p}(0.8,0.4) & \mathrm{p}(0.8,0.4) & \mathrm{p}(0.6,0.7)
\end{array}\right. \\
& \begin{array}{lllll}
p(0.8,0.5) & p(0.9,0.2) & p(0.7,0.4) & p(0.7,0.6) & p(0.7,0.5)
\end{array} \\
& \begin{array}{llllll}
\mathrm{p}(0.4,0.8) & \mathrm{p}(0.3,0.6) & \mathrm{p}(0.7,0.5) & \mathrm{p}(0.8,0.3) & \mathrm{p}(0.5,0.7)
\end{array} \text {; } \\
& \begin{array}{lllll}
\mathrm{p}(0.4,0.2) & \mathrm{p}(0.8,0.3) & \mathrm{p}(0.8,0.5) & \mathrm{p}(0.6,0.3) & \mathrm{p}(0.4,0.8)
\end{array} \\
& \begin{array}{llllll}
\mathrm{p}(0.7,0.3) & \mathrm{p}(0.6,0.4) & \mathrm{p}(0.8,0.5) & \mathrm{p}(0.8,0.3) & \mathrm{p}(0.6,0.7)
\end{array} \\
& \begin{array}{lllll}
\mathrm{p}(0.8,0.3) & \mathrm{p}(0.8,0.5) & \mathrm{p}(0.8,0.3) & \mathrm{p}(0.6,0.7) & \mathrm{p}(0.8,0.5)
\end{array} \\
& \begin{array}{lllll}
\mathrm{p}(0.6,0.7) & \mathrm{p}(0.6,0.5) & \mathrm{p}(0.9,0.3) & \mathrm{p}(0.6,0.4) & \mathrm{p}(0.4,0.6)
\end{array} \\
& \begin{array}{lllll}
\mathrm{p}(0.8,0.4) & \mathrm{p}(0.6,0.7) & \mathrm{p}(0.7,0.7) & \mathrm{p}(0.8,0.5) & \mathrm{p}(0.9,0.2)
\end{array} \\
& U_{4 \times 10}^{(3)}=\left(\begin{array}{lllll}
\mathrm{p}(0.7,0.7) & \mathrm{p}(0.7,0.6) & \mathrm{p}(0.7,0.6) & \mathrm{p}(0.6,0.7) & \mathrm{p}(0.6,0.6) \\
\mathrm{p}(0.7,0.5) & \mathrm{p}(0.7,0.6) & \mathrm{p}(0.6,0.6) & \mathrm{p}(0.5,0.7) & \mathrm{p}(0.5,0.6) \\
\mathrm{p}(0.6,0.7) & \mathrm{p}(0.4,0.8) & \mathrm{p}(0.8,0.5) & \mathrm{p}(0.3,0.8) & \mathrm{p}(0.3,0.8) \\
\mathrm{p}(0.6,0.7) & \mathrm{p}(0.6,0.7) & \mathrm{p}(0.7,0.5) & \mathrm{p}(0.6,0.7) & \mathrm{p}(0.5,0.6)
\end{array} ;\right. \\
& \begin{array}{llllll}
\mathrm{p}(0.8,0.5) & \mathrm{p}(0.5,0.8) & \mathrm{p}(0.7,0.7) & \mathrm{p}(0.7,0.7) & \mathrm{p}(0.7,0.6)
\end{array} \\
& \begin{array}{lllll}
\mathrm{p}(0.5,0.5) & \mathrm{p}(0.5,0.5) & \mathrm{p}(0.7,0.6) & \mathrm{p}(0.6,0.7) & \mathrm{p}(0.6,0.6)
\end{array} \\
& \begin{array}{lllll}
\mathrm{p}(0.6,0.7) & \mathrm{p}(0.5,0.7) & \mathrm{p}(0.5,0.7) & \mathrm{p}(0.4,0.8) & \mathrm{p}(0.3,0.8)
\end{array} \\
& \begin{array}{lllll}
\mathrm{p}(0.6,0.7) & \mathrm{p}(0.6,0.8) & \mathrm{p}(0.7,0.7) & \mathrm{p}(0.4,0.8) & \mathrm{p}(0.6,0.6)
\end{array} \\
& \left(\begin{array}{llllll}
\mathrm{p}(0.4,0.5) & \mathrm{p}(0.4,0.5) & \mathrm{p}(0.4,0.4) & \mathrm{p}(0.6,0.5) & \mathrm{p}(0.6,0.5)
\end{array}\right. \\
& U_{4 \times 10}^{(4)}=\left(\begin{array}{lllll}
\mathrm{p}(0.9,0.4) & \mathrm{p}(0.8,0.3) & \mathrm{p}(0.8,0.7) & \mathrm{p}(0.6,0.4) & \mathrm{p}(0.4,0.4)
\end{array}\right. \\
& U_{4 \times 10}^{(4)}=\begin{array}{lllll}
\mathrm{p}(0.9,0.4) & \mathrm{p}(0.8,0.3) & \mathrm{p}(0.8,0.7) & \mathrm{p}(0.6,0.4) & \mathrm{p}(0.4,0.4) \\
\mathrm{p}(0.6,0.7) & \mathrm{p}(0.6,0.6) & \mathrm{p}(0.6,0.6) & \mathrm{p}(0.4,0.3) & \mathrm{p}(0.2,0.3)
\end{array} \\
& \begin{array}{lllll}
\mathrm{p}(0.1,0.3) & \mathrm{p}(0.2,0.7) & \mathrm{p}(0.2,0.3) & \mathrm{p}(0.8,0.4) & \mathrm{p}(0.8,0.3)
\end{array} \\
& \begin{array}{llllll}
\mathrm{p}(0.4,0.5) & \mathrm{p}(0.6,0.3) & \mathrm{p}(0.6,0.3) & \mathrm{p}(0.6,0.3) & \mathrm{p}(0.4,0.4)
\end{array} \\
& \begin{array}{lllll}
\mathrm{p}(0.8,0.5) & \mathrm{p}(0.2,0.3) & \mathrm{p}(0.4,0.4) & \mathrm{p}(0.5,0.4) & \mathrm{p}(0.8,0.3)
\end{array} \\
& \begin{array}{lllll}
\mathrm{p}(0.6,0.5) & \mathrm{p}(0.4,0.3) & \mathrm{p}(0.8,0.5) & \mathrm{p}(0.8,0.3) & \mathrm{p}(0.6,0.5)
\end{array} \\
& \begin{array}{lllll}
\mathrm{p}(0.2,0.3) & \mathrm{p}(0.8,0.2) & \mathrm{p}(0.2,0.3) & \mathrm{p}(0.7,0.5) & \mathrm{p}(0.2,0.5)
\end{array} \\
& U_{4 \times 10}^{(5)}=\left(\begin{array}{lllll}
\mathrm{p}(0.7,0.5) & \mathrm{p}(0.4,0.6) & \mathrm{p}(0.5,0.3) & \mathrm{p}(0.3,0.5) & \mathrm{p}(0.8,0.3) \\
\mathrm{p}(0.5,0.2) & \mathrm{p}(0.6,0.4) & \mathrm{p}(0.6,0.4) & \mathrm{p}(0.6,0.3) & \mathrm{p}(0.5,0.4) \\
\mathrm{p}(0.6,0.3) & \mathrm{p}(0.5,0.2) & \mathrm{p}(0.6,0.3) & \mathrm{p}(0.5,0.4) & \mathrm{p}(0.6,0.3) \\
\mathrm{p}(0.6,0.4) & \mathrm{p}(0.7,0.2) & \mathrm{p}(0.7,0.3) & \mathrm{p}(0.7,0.4) & \mathrm{p}(0.4,0.2)
\end{array}\right. \\
& \begin{array}{lllll}
\mathrm{p}(0.4,0.3) & \mathrm{p}(0.7,0.6) & \mathrm{p}(0.3,0.8) & \mathrm{p}(0.4,0.5) & \mathrm{p}(0.3,0.6)
\end{array} \\
& \begin{array}{lllll}
\mathrm{p}(0.7,0.4) & \mathrm{p}(0.5,0.3) & \mathrm{p}(0.5,0.4) & \mathrm{p}(0.7,0.3) & \mathrm{p}(0.6,0.4)
\end{array} \\
& \begin{array}{lllll}
\mathrm{p}(0.5,0.3) & \mathrm{p}(0.6,0.5) & \mathrm{p}(0.3,0.7) & \mathrm{p}(0.4,0.3) & \mathrm{p}(0.4,0.5)
\end{array} \\
& \begin{array}{lllll}
\mathrm{p}(0.7,0.2) & \mathrm{p}(0.5,0.2) & \mathrm{p}(0.7,0.3) & \mathrm{p}(0.8,0.2) & \mathrm{p}(0.7,0.2)
\end{array}
\end{aligned}
$$

Using the proposed method, the steps of the PDS selection are as follows:

Step 1: Construction of Pythagorean fuzzy evaluation matrix through aggregating the evaluation information of five experts. By Definition 5, the Pythagorean fuzzy evaluation matrix is determined

$$
U_{4 \times 10}=\left(\mathrm{p}_{i j}\left(\sum_{l=1}^{5} W_{l} u_{i j}^{(l)}, \sum_{l=1}^{5} W_{l} v_{i j}^{(l)}\right)\right)_{4 \times 10}
$$

$\left(\begin{array}{llllll}\mathrm{p}(0.60,0.54) & \mathrm{p}(0.56,0.58) & \mathrm{p}(0.60,0.44) & \mathrm{p}(0.58,0.46) & \mathrm{p}(0.64,0.46)\end{array}\right.$ $\begin{array}{lllll}\mathrm{p}(0.74,0.40) & \mathrm{p}(0.76,0.38) & \mathrm{p}(0.68,0.50) & \mathrm{p}(0.62,0.48) & \mathrm{p}(0.58,0.46)\end{array}$ $\begin{array}{lllll}\mathrm{p}(0.56,0.58) & \mathrm{p}(0.46,0.50) & \mathrm{p}(0.66,0.44) & \mathrm{p}(0.56,0.42) & \mathrm{p}(0.42,0.48)\end{array}$ $\begin{array}{lllll}\mathrm{p}(0.44,0.36) & \mathrm{p}(0.60,0.48) & \mathrm{p}(0.62,0.38) & \mathrm{p}(0.66,0.42) & \mathrm{p}(0.56,0.44)\end{array}$ $\begin{array}{lllll}\mathrm{p}(0.58,0.38) & \mathrm{p}(0.62,0.50) & \mathrm{p}(0.60,0.54) & \mathrm{p}(0.58,0.44) & \mathrm{p}(0.52,0.52)\end{array}$ $\begin{array}{lllll}\mathrm{p}(0.68,0.38) & \mathrm{p}(0.56,0.42) & \mathrm{p}(0.64,0.44) & \mathrm{p}(0.60,0.48) & \mathrm{p}(0.70,0.40)\end{array}$ $\begin{array}{lllll}\mathrm{p}(0.62,0.52) & \mathrm{p}(0.56,0.46) & \mathrm{p}(0.66,0.48) & \mathrm{p}(0.58,0.40) & \mathrm{p}(0.42,0.58)\end{array}$ $\begin{array}{lllll}\mathrm{p}(0.60,0.42) & \mathrm{p}(0.66,0.46) & \mathrm{p}(0.60,0.46) & \mathrm{p}(0.62,0.44) & \mathrm{p}(0.60,0.38)\end{array}$

Step 2: Based on formulas (11) and (12), the best suitable PDS and the worst suitable PDS can be calculated as follow:

$$
\begin{aligned}
& O^{+}=\{(0.56,0.58),(0.76,0.38),(0.66,0.44), \\
& \\
&(0.56,0.42),(0.42,0.48),(0.68,0.38), \\
&(0.66,0.46),(0.64,0.44),(0.60,0.48),(0.70,0.40)\} ;
\end{aligned}
$$




$$
\begin{aligned}
O^{-}= & (0.74,0.40),(0.46,0.50),(0.60,0.44), \\
& (0.66,0.42),(0.64,0.46),(0.62,0.52), \\
& (0.56,0.46),(0.60,0.54),(0.62,0.44),(0.42,0.58)\} .
\end{aligned}
$$

Step 3: By formula (13), the 3-type PFSs weighted similarity measures between each PDS $o_{i}$ and the best suitable PDS $O^{+}$are calculated below:

$$
\begin{aligned}
& \mathrm{r}_{5}\left(o_{1}, O^{+}\right)=0.8806 ; \mathrm{r}_{5}\left(o_{2}, O^{+}\right)=0.9309 ; \\
& \mathrm{r}_{5}\left(o_{3}, O^{+}\right)=0.8857 ; \mathrm{r}_{5}\left(o_{4}, O^{+}\right)=0.8989 .
\end{aligned}
$$

Analogously, we obtain that the similarity measures between the $\operatorname{PDS} o_{i}$ and the worst suitable $O^{-}$are as follows:

$$
\begin{aligned}
& \mathrm{r}_{5}\left(o_{1}, O^{-}\right)=0.9080 ; \mathrm{r}_{5}\left(o_{2}, O^{-}\right)=0.8674 ; \\
& \mathrm{r}_{5}\left(o_{3}, O^{-}\right)=0.9209 ; \mathrm{r}_{5}\left(o_{4}, O^{-}\right)=0.8844
\end{aligned}
$$

Step 4: From formula (15), the relative closeness value $r_{i}$ from the PDS $o_{i}$ with regard to the best suitable PDS $O^{+}$is calculated:

$$
r_{1}=0.5077 ; r_{2}=0.4823 ; r_{3}=0.5097 ; r_{4}=0.4959 \text {. }
$$

Step 5: According to the results in Step 4, we obtain $r_{3}>r_{1}>r_{4}>r_{2}$, that is, $\mathrm{EPC}>\mathrm{DB}>\mathrm{DBB}>\mathrm{CM}$. Therefore, EPC is the best choice among the four options. According to the sorted results, it is suitable to accept for practical application.

The research plays an important role to give a reasonable reference for owners using the proposed ways in selection of PDSs. The existing literature about PDS selection methods, such as Alhazmi and McCaffer (2000), Chen et al. (2011) and Li et al. (2015), always require the experts to provide the fuzzy characteristic of criteria with the sum of non-membership and membership degrees smaller than one. It actually constraints the judgement of experts in practical. However, it is an inevitable reality when experts give their evaluation preferences with a sum from membership and non-membership degrees is larger than one, unlike discussed in intuitionistic fuzzy set. PFS, which extends IFS, gives a wide thinking space for experts with a more general condition, that is, $u_{A}^{2}+v_{A}^{2} \leq 1$. As shown in Figure 4, the filed $I$ is the thinking space using IFS theory, and the filed I+II when using PFS theory.

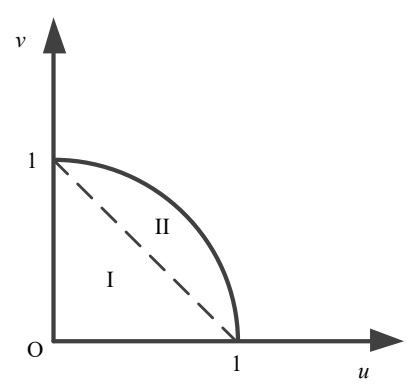

Figure 4. The Fields of IFS and PFS

\section{Conclusions}

In construction projects, PDS defined the relationship between these stakeholders. It includes contractual and arrangements that allow the owner to gain a complete facility that meet their needs. The success or failure of a construction project is the selection approach of a PDS. Multi-criteria decision making method was an efficient tool for PDS selection problem.

This research reviewed the literature on PDS selection decision making methods and found a research gap in knowledge related to PDS selection through a Pythagorean fuzzy TOPSIS approach using the proposed similarity measure. Based on it, the main contribution of this paper are as follows. (1) Three new similarity measures under PFSs based on minimum and maximum operators are presented, and their properties are investigated. (2) An improved TOPSIS method using the proposed similarity measures was established. (3) To obtain suitable PDS considering completely the "true psychological" behavior of decision experts, the selection model of PDS under Pythagorean fuzzy setting is given based on improved TOPSIS approach.

In general, the PDS selection problem is one key task for owners, and the MCDM problem is a hotspot in academic filed because of uncertainty in practical. The Pythagorean fuzzy set has aroused more and more attention. Meanwhile, similarity measure, which describes the relatedness between PFSs, is an important tool to measure similarity degree between two objects. Integrated their advantage, this paper established the selection model of PDS and applied it to a case study about selection of project delivery system. It has great theoretical and realistic significance for owners to select appropriate PDS. In the later study research, interval Pythagorean fuzzy environment and others application areas could be considered for the proposed method.

\section{Acknowledgments}

The authors acknowledge with gratitude the National Key R\&D Program of China (No.2018YFC0406905), MOE (Ministry of Education in China) Project of Humanities and Social Sciences (No.19YJC630078), Youth Talents Teachers Scheme of Henan Province Universities (No.2018GGJS080), the National Natural Science Foundation of China (\#project No.71302191), the Foundation for Distinguished Young Talents in Higher Education of Henan (Humanities \& Social Sciences), China (No.2017-cxrc-023). This study would not have been possible without their financial support.

\section{Conflicts of Interest}

The authors declare that they have no conflicts of interest. 


\section{References}

Aikhuele, D., \& Turan, F. (2017). Extended TOPSIS model for solving multi-attribute decision making problems in engineering. Decision Science Letters, 6(4), 365-376. https://doi.org/10.5267/j.dsl.2017.2.002

Alhazmi, T., \& Mccaffer, R. (2000). Project Procurement System Selection Model. Journal of Construction Engineering and Management, 126(3), 176-184. https://doi.org/10.1061/(ASCE)0733-9364(2000)126:3(176)

An, X. W., Wang Z. F., Li, H. M., \& Ding, J. Y. (2018) Project Delivery System Selection with Interval-Valued Intuitionistic Fuzzy Set Group Decision-Making Method. Group Decision and Negotiation, 27(4), 689-707. https://doi.org/10.1007/s10726-018-9581-y

ASCE. (1988). Quality in the Constructed Project: A Guideline for Owners, Designers, and Constructors, http://dx.doi.org/ 10.1061/9780784411896.

Atanassov, K. T. (1986). Intuitionistic fuzzy sets. Fuzzy Sets and Systems, 20(1), 87-96. https://doi.org/10.1016/S01650114(86)80034-3

Atanassov, K. T. (1989). More on intuitionistic fuzzy sets. Fuzzy Sets and Systems, 33(1), 37-45. https://doi.org/10.1016/ 0165-0114(89)90215-7

Belton, V., \& Stewart, T. J. (2002). Multiple criteria decision analysis: an integrated approach. International, 142(6), 192-202. https://doi.org/10.1007/978-1-4615-1495-4

Blayse, A. M., \& Manley, K. (2004). Key influences on construction innovation. Construction Innovation, 4(3), 143-154. https://doi.org/10.1108/14714170410815060

Boran, F. E., Genc, S., Kurt, M., \& Akay, D. (2009). A multi-criteria intuitionistic fuzzy group decision making for supplier selection with TOPSIS method. Expert Systems with Applications, 36(8), 11363-11368. https://doi.org/10.1016/j.eswa.2009.03.039

Chan, A., Yung, E., Lam, P., Tam, C. M., \& Cheung, S. (2001). Application of Delphi method in selection of procurement systems for construction projects. Construction Management \& Economics, 19(7), 699-718. https://doi.org/10.108 0/01446190110066128

Chen, S. M., Cheng, S., \& Lan, T. C. (2016). Multi-criteria decision making based on the TOPSIS method and similarity measures between intuitionistic fuzzy values. Information Sciences, 367, 279-295. https://doi.org/10.101 6/j.ins.20 16.05.044

Chen, T. Y. (2015). The inclusion-based TOPSIS method with interval-valued intuitionistic fuzzy sets for multiple criteria group decision making. Applied Soft Computing, 26, 57-73. https://doi.org/10.1016/j.asoc.2014.09.015

Chen, Y. Q., Lu, H., Lu, W., \& Zhang, N. (2010). Analysis of project delivery systems in Chinese construction industry with data envelopment analysis (DEA). Engineering, 17(6), 598-614. https://doi.org/10.1108/09699981011090215

Chen, Y., Liu, J., Li, B., \& Lin, B. (2011). Project delivery system selection of construction projects in China. Expert Systems with Applications, 38(5), 5456-5462. https://doi.org/10.1016/j.eswa.2010.10.008

Fahmi, A., Abdullah, S., Amin, F., \& Siddiqui, N. (2017). Aggregation operators on triangular cubic fuzzy numbers and its application to multi-criteria decision making problems. Journal of Intelligent and Fuzzy Systems, 33(6), 33233337. https://doi.org/10.3233/JIFS-162007

Gitinavard, H., Pishvaee, M. S., \& Jalalvand, F. (2017). A hierarchical multi-criteria group decision-making method based on TOPSIS and hesitant fuzzy information. International Journal of Applied Decision Sciences, 10(3), 213. https://doi.org/10.1504/IJADS.2017.085084

Hanine, M., Boutkhoum, O., Tikniouine, A., \& Agouti, T. (2016). Application of an integrated multi-criteria decision making AHP-TOPSIS methodology for ETL software selection. Springerplus, 5(1). https://doi.org/10.1186/s40064016-1888-z

Hwang, C. L., \& Yoon, K. (1981). Methods for Multiple Attribute Decision Making. Springer, Berlin, Heidelberg, https://doi.org/10.1007/978-3-642-48318-9

Hong, H. K., Kim, J. S., Kim, T., \& Leem, B. H. (2008). The effect of knowledge on system integration project performance. Industrial Management and Data Systems, 108(3), 385-404. https://doi.org/10.1108/0263 5570810 858787

Joshi, D., \& Kumar, S. (2016). Interval-valued intuitionistic hesitant fuzzy Choquet integral based TOPSIS method for multi-criteria group decision making. European Journal of Operational Research, 248(1), 183-191. https://doi.org/10.1016/S0263-7863(01)00032-1 
Limin Su, Huimin Li, Yongchao Cao, Lelin Lv. Project Delivery System Decision Making using Pythagorean...

Khalil, M. (2002). Selecting the appropriate project delivery method using AHP. International Journal of Project Management, 20(6), 469-474. https://doi.org/10.1016/S0263-7863(01)00032-1

Li, H., Qin, K., \& Li, P. (2015). Selection of project delivery approach with unascertained model. Kybernetes, 44(2), 238252. https://doi.org/10.1108/K-01-2014-0012

Li, W., \& Wu, C. (2016). A Multi-criteria Interval-Valued Intuitionistic Fuzzy Set TOPSIS Decision-Making Approach Based on the Improved Score Function. Journal of Intelligent Systems, 25(2), 239-250.

Liang, D., \& Xu, Z. (2017). The New Extension of TOPSIS Method for Multiple Criteria Decision Making with Hesitant Pythagorean Fuzzy Sets. Applied Soft Computing, 60. https://doi.org/10.1016/j.asoc.2017.06.034

Liang, D., Xu, Z., Liu, D., \& Wu, Y. (2018). Method for Three-Way Decisions using Ideal TOPSIS Solutions at Pythagorean Fuzzy Information. Information Sciences, 435, 282-295. https://doi.org/10.1016/j.ins.2018.01.015

Liu, B., Huo, T., Shen, Q., Yang, Z., Meng, J., \& Xue, B. (2015). Which Owner Characteristics Are Key Factors Affecting Project Delivery System Decision Making? Empirical Analysis Based on the Rough Set Theory. Journal of Management in Engineering, 31(4), 05014018. https://doi.org/10.1061/(ASCE)ME.1943-5479.0000298

Liu, Q. H. (2014). An extended TOPSIS method for multiple attribute decision making problems with unknown weight based on 2-dimension uncertain linguistic variables. Journal of Intelligent and Fuzzy Systems, 27(5), 2221-2230. http://dx.doi.org/10.3233/ifs-141186

Love, P., Skitmore, M., \& Earl, G. (2014). Selecting a suitable procurement method for a building project. Construction Management and Economics, 16(2), 221-233. https://doi.org/10.1080/014461998372501

Mafakheri, F., Dai, L., Slezak, D., \& Nasiri, F. (2007). Project Delivery System Selection under Uncertainty: Multicriteria Multilevel Decision Aid Model. Journal of Management in Engineering, 23(4), 200-206. https://doi.org/10. 1061/(ASCE)0742-597X(2007)23:4(200)

Mahdi, I. M., \& Alreshaid, K. (2005). Decision support system for selecting the proper project delivery method using analytical hierarchy process (AHP). International Journal of Project Management, 23(7), 564-572. https://doi.org/10.1016/j.ijproman.2005.05.007

Mollaoglukorkmaz, S., Swarup, L., \& Riley, D. (2013). Delivering Sustainable, High-Performance Buildings: Influence of Project Delivery Methods on Integration and Project Outcomes. Journal of Management in Engineering-ASCE, 29(1),71-78. https://doi.org/10.1061/(ASCE)ME.1943-5479.0000114

Nehi, H. M., \& Keikha, A. (2016). TOPSIS and Choquet integral hybrid technique for solving MAGDM problems with interval type-2 fuzzy numbers. Journal of Intelligent and Fuzzy Systems, 30(3), 1301-1310. https://doi.org/10. 3233/IFS-152044

Ng, S., Chen, S. E., \& Luu, D. (2005). Formulating Procurement Selection Criteria through Case-Based Reasoning Approach. Journal of Computing in Civil Engineering, 19(3), 269-276. https://doi.org/10.1061/(ASCE)08873801(2005)19:3(269)

Onat, N., Gumus, S., Kucukvar, M., \& Tatari, O. (2016). Application of the TOPSIS and intuitionistic fuzzy set approaches for ranking the life cycle sustainability performance of alternative vehicle technologies. Sustainable Production and Consumption, 6, 12-25. https://doi.org/10.1016/j.spc.2015.12.003

Oyetunji, A., \& Anderson, S. (2006). Relative Effectiveness of Project Delivery and Contract Strategies. Journal of Construction Engineering and Management, 132(1), 3-13. https://doi.org/10.1061/(ASCE)0733-9364(2006) $132: 1(3)$

Podviezko, A., \& Podvezko, V. (2014). Absolute and Relative Evaluation of Socio-Economic Objects Based on Multiple Criteria Decision Making Methods. Inzinerine Ekonomika-Engineering Economics, 25, 522-529. https://doi.org/10. 5755/j01.ee.25.5.6624

Peng, X., \& Yang, Y. (2015). Some Results for Pythagorean Fuzzy Sets. International Journal of Intelligent Systems, 30(11), https://doi.org/10.1002/int.21738

Potharaju, S. P., \& Sreedevi. M. (2018). An unsupervised approach for selection of candidate feature set using filter based techniques. Gazi University Journal of Science, 31(3), 789-799.

Stevic, Z., Vasiljevic, M., Zavadskas, E. K., Sremac, S., \& Turskis, Z. (2018). Selection of Carpenter Manufacturer using Fuzzy EDAS Method. Inzinerine Ekonomika-Engineering Economics, 29(3), 281-290. https://doi.org/10.5755/ j01.ee.29.3.16818

Pourahmadi, A., Ebadi, T., \& Nikazar, M. (2017). Industrial Wastes Risk Ranking with TOPSIS, Multi Criteria Decision Making Method. Civil Engineering Journal, 3(6), 372-381. https://doi.org/10.28991/cej-2017-00000098 
Qiang, M., Wen, Q., Jiang, H., \& Yuan, S. (2015). Factors governing construction project delivery selection: A content analysis. International Journal of Project Management, 33(8), 1780-1794. https://doi.org/10.1016/j.ijproman. 2015.07.001

Ren, F., Kong, M., \& Pei, Z. (2018). A New Hesitant Fuzzy Linguistic TOPSIS Method for Group Multi-Criteria Linguistic Decision Making. Symmetry, 9(12), 289. https://doi.org/10.3390/sym9120289

Shane, J., Bogus, S., \& Molenaar, K. (2013). Municipal Water/Wastewater Project Delivery Performance Comparison. Journal of Management in Engineering, 29(3), 251-258. https://doi.org/10.1061/(ASCE)ME.1943-5479.0000139

Shi, Q., Zhou, Y., Xiao, C., Chen, R., \& Zuo, J. (2014). Delivery risk analysis within the context of program management using fuzzy logic and DEA: A China case study. International Journal of Project Management, 32(2), $341-349$. https://doi.org/10.1016/j.ijproman.2013.05.002

Tian, Z., Zhang, H., Wang, J., Wang, J., \& Chen, X. (2015). Multi-criteria decision-making method based on a crossentropy with interval neutrosophic sets. International Journal of Systems Science, 47. https://doi.org/10.1080/0020 7721.2015.1102359

Wang, L., An, X., \& Li, H. (2014). Applying fuzzy set model for selecting project delivery system. Wit Transactions on Modelling and Simulation, 60, 1301-1308. https://doi.org/10.2495/SMTA20141502

Yager, R. R. (2014). Pythagorean Membership Grades in Multi-criteria Decision Making. IEEE Transactions on Fuzzy Systems, 22(4), 958-965. https://doi.org/10.1109/TFUZZ.2013.2278989

Yager R R. (2013). Pythagorean fuzzy subsets. Ifsa World Congress and Nafips Meeting, 7586(2), 57-61. https://doi.org/10.1109/IFSA-NAFIPS.2013.6608375

Zadeh, L. A. (1965). Fuzzy sets, information and control. Information and Control, 8(3), 338-353. https://doi.org/10. 1016/S0019-9958(65)90241-X

Zhang, L., Xu, Y., Yeh, C. H., He, L., \& Zhou, D. Q. (2017). Bi-TOPSIS: A New Multi-criteria Decision Making Method for Interrelated Criteria With Bipolar Measurement. IEEE Transactions on Systems Man and Cybernetics Systems, 47(12), 3272-3283. https://doi.org/10.1109/TSMC.2016.2573582

Zhang, X., \& Xu, Z. (2015). Extension of TOPSIS to Multiple Criteria Decision Making with Pythagorean Fuzzy Sets. International Journal of Intelligent Systems, 29(12), 1061-1078. https://doi.org/10.1002/int.21676

Zhou, H., Wang, J. Q., \& Zhang, H. Y. (2015). Grey stochastic multi-criteria decision-making based on regret theory and TOPSIS. International Journal of Machine Learning and Cybernetics, 8(2), 1-14. https://doi.org/10.1007/s13042015-0459-x

The article has been reviewed. Received in November 2018; accepted in October 2019. 